\title{
Racionalidad y discernimiento: un debate filosófico-jurídico sobre la alteración de criterios para la definición de la capacidad civil*
}

\author{
Maria Claudia Cachapuz* \\ Recibido: 05 de septiembre de 2016 • Aprobado: 09 de noviembre de 2018 \\ https://doi.org/10.22395/ojum.v17n34a7
}

\begin{abstract}
RESUMEN
A partir del análisis de las distintas corrientes filosóficas, este texto discute el concepto de autonomía en el caso de conflictos jurídicos complejos, como en la definición de la capacidad civil, por la reciente entrada en vigor de la Ley no. 13.146/15 (Estatuto de la persona con deficiencia) en el ordenamiento jurídico brasileño. Se debate sobre la medida del establecimiento de límites apriorísticos a un ejercicio de libertad intersubjetiva y sobre cómo deben ofrecerse razones suficientes a la restricción de toda y cualquier libertad. Al mismo tiempo, hay la preocupación por tornar potente la autonomía de la persona, como un principio relevante para la construcción de la moral en la sociedad contemporánea. Esto permite el cuestionamiento a la aprobación reciente del Estatuto de la persona con deficiencia en Brasil, por suprimir los incisos del artículo $3^{\circ}$ del Código Civil brasileño, extirpando, normativamente, el criterio del discernimiento para la determinación de la capacidad civil. Teniendo por base el discurso jurídico, se apunta como fundamental, para fines de interpretación, el rescate del concepto de discernimiento para la promoción del libre desarrollo de la personalidad humana.
\end{abstract}

Palabras clave: argumentación; racionalidad; capacidad civil.

Artículo realizado como producto de reflexión del Grupo de Enseñanza Derecho, Ambiente y Nuevas Tecnologías del Máster en Derecho y Sociedad de la Universidad La Salle, Canoas/Brasil, en julio de 2017.

** Graduada en Ciencias Jurídicas, Universidade Federal do Rio Grande do Sul, Porto Alegre, Brasil; doctora en Derecho Civil, Universidade Federal do Rio Grande do Sul, Porto Alegre Brasil, jueza de derecho del Tribunal de Justicia de Rio Grande do Sul, Brasil; profesora de la Universidade Federal do Rio Grande do Sul, Brasil y del Máster en Derecho y Sociedad de la Universidad La Salle, Canoas, Brasil. Correo electrónico: mcmcachapuz@tj.rs.gov.br 


\title{
Rationality and discernment: a philosophical-legal debate on the alteration of criteria for the definition of civil capacity
}

\begin{abstract}
Based on the analysis of the different philosophical currents, this text discusses the concept of autonomy in the case of complex legal conflicts, as in the definition of civil capacity, due to the recent entry into force of Law no. 13,146/15 (Statute of the Person with Deficiency) in the Brazilian legal system. There is debate on the measure of establishing aprioristic limits to an exercise of intersubjective freedom and on how sufficient reasons should be offered to the restriction of any and all freedom. At the same time, there is the concern to make the autonomy of the person powerful, as a relevant principle for the construction of morality in contemporary society. This allows the questioning of the recent approval of the Statute of the person with deficiency in Brazil, by suppressing the paragraphs of art. 3 of the Brazilian Civil Code, extirpating, normatively, the criterion of discernment for the determination of civil capacity. Based on the juridical discourse, the rescue of the concept of discernment for the promotion of the free development of the human personality is pointed out as fundamental, for purposes of interpretation.
\end{abstract}

Keywords: argumentation; rationality; civil capacity.

\section{Racionalidade e discernimento: um debate filosófico-jurídico sobre a alteração de critérios para a definição da capacidade civil}

\begin{abstract}
RESUMO
A partir da análise das diferentes correntes filosóficas, este texto discute o conceito de autonomia no caso de conflitos jurídicos complexos, como na definição da capacidade civil, pela recente entrada em vigor da Lei 13.146/15 (Estatuto da pessoa com deficiência) no ordenamento jurídico brasileiro. Debate-se sobre a medida do estabelecimento de limites apriorísticos para um exercício de liberdade intersubjetiva e sobre como razões suficientes à restrição de toda e qualquer liberdade devem ser oferecidas. Ao mesmo tempo, existe a preocupação de tornar potente a autonomia da pessoa, como um princípio relevante para a construção da moral na sociedade contemporânea. Isso permite o questionamento da recente aprovação do Estatuto da pessoa com deficiência no Brasil, por suprimir os incisos do $3^{\circ}$ artigo do Código Civil Brasileiro, excluindo, normativamente, o critério do discernimento para a determinação da capacidade civil. Baseado no discurso jurídico, aponta-se como fundamental, para fins de interpretação, o resgate do conceito de discernimento para a promoção do livre desenvolvimento da personalidade humana.
\end{abstract}

Palavras-chave: argumentação; racionalidade; capacidade civil. 


\section{INTRODUCCIÓN}

En el año de 2015, en plena estación de tren de la ciudad de Río de Janeiro, Brasil, un dilema del campo filosófico dejó de ser parte de las preocupaciones y de la prueba metafísica - aunque se proponga con carácter hipotético- para ganar espacio en la construcción de un juicio de evidencia real: un maquinista quedó autorizado, por la autoridad responsable de una concesionaria de prestación de servicio público ferroviario, para pasar con el tren en movimiento sobre el cuerpo de un vendedor ambulante atropellado hacía instantes en las vías del tren (Duarte, 2015). Para tal determinación, algunas condiciones fácticas fueron ofrecidas a las instancias decisorias para la rápida ponderación efectuada: (i) la ausencia aparente de cualquier señal de vida del vendedor ambulante en virtud del atropellamiento, aunque no haya sido comprobada clínicamente una situación de muerte hasta el momento de la toma de decisión; (ii) el atraso constatado para la atención médica y retirada del cuerpo del local del atropellamiento, denunciando la efectiva demora por parte de la autoridad de tránsito en el servicio de emergencias en un horario de tráfico intenso de pasajeros; (iii) la constatación de que, con la eventual detención del tren, otros dos trenes serían afectados en los períodos computados para la prestación del servicio de transporte al público, retardando el transporte de cerca de seis mil usuarios de la estación en esa hora; (iv) la verificación de que la distancia existente entre las vías del tren y la primera altura de la base del vagón sería suficiente para evitar el efectivo roce entre el cuerpo extendido y el vehículo en movimiento - para alejar la posible tipificación de un delito de vilipendio de cadáver (artículo 212 del Código Penal brasileño) —; (v) la evaluación previa de que el atropellamiento podría haber sido motivado por la víctima, echándose sobre las vías del tren para provocar la propia muerte — por lo tanto, suponiéndose un deseo autónomo de provocar el resultado muerte-; (vi) la real posibilidad de parar con anticipación el tren, evitándose el dilema moral, pero causándose un probable perjuicio, inclusive económico, a los pasajeros que no dieron causa directa al incidente.

La decisión fue adoptada con suficiente consulta a la autoridad competente y con espacio disponible para la reflexión. La opción adoptada por el maquinista de forma consciente, e instantánea, fue la de proseguir con el movimiento sobre las vías, adhiriendo a un juicio fundado en una ética utilitarista. Para el caso, hubo la ponderación de los medios disponibles al alcance de un menor perjuicio para la colectividad aún productiva implicada en el proceso - la autoridad estatal, la autoridad delegada, el maquinista del tren, los pasajeros-. Como en todo ejercicio decisorio, para efecto de aplicación de una ética funcionalista - en torno a un proyecto estratégico de alcance de finalidades-, la intersubjetividad presupuesta en la prueba de la universalidad perdió fuerza, a priori, para la obtención de un proyecto colectivo. Por el ejercicio pragmático, literalmente, la conducta de pasar por encima de la persona quedó considerada, para el caso, como una con- 
dición fáctica ponderable en momento de tráfico intenso.

No es diferente la propuesta de examen metafísico ofrecida por Foot (2002) sobre el enfrentamiento de dilemas morales y de la circunstancia ética, cuando son analizadas virtudes, deseos e intereses particulares. En el dilema de Foot, un tranvía está fuera de control en una carretera. En el camino, cinco personas amarradas en la pista. Es posible accionar un mecanismo que desviará el tranvía para un trayecto diferente, en el que hay apenas una persona igualmente amarrada. ¿En esa hipótesis, debe ser adoptado el desvío? ¿Cabe sostener la corrección de una decisión que interceda en el curso natural de la colisión del tranvía para afectar un número inferior de personas?

En una visión funcionalista del problema, la respuesta apoyada en el análisis cuantitativo de los problemas afectados por el tranvía autorizaría la conclusión por la adopción del desvío. Siguiendo el ejemplo adoptado en la solución brasileña, la opción por una filosofía utilitarista exige, necesariamente en todos los niveles de enfrentamiento de dilemas filosóficos por el ejercicio de argumentación, un abordaje distinto con relación al tema de la restricción a derechos subjetivos —y, de forma más específica, a derechos fundamentales - y a los derechos de la personalidad. Requiere la creencia en la desacralización de la concepción de vida humana, como defiende Singer (2003). O sea, que se parta de una inversión del análisis universal presupuesto en la razón práctica de los modernos, para alcanzar una ética práctica distinta. La decisión a ser tomada presupone, antes de cualquier prueba de universalidad, un "raciocinio pre-ético", en que las condiciones a ser ponderadas se refieran, únicamente, a intereses de los afectados por la decisión. El intuito es de elegir el modo de actuar que permita obtener las "mejores consecuencias" (Singer, 2009, p. 25). El enfoque utilitarista requiere la adopción de una conducta ética mínima en concreto: "una primera etapa que alcanzamos al universalizar la toma de decisiones interesadas" (Singer, 2009, p. 26). Apenas por buenas razones, suficientemente demostradas, es que se podría ir más allá de un raciocinio estratégico, acogiendo un presupuesto de universalización de conducta: "hasta que no nos sean ofrecidas estas razones, tenemos motivos para seguir siendo utilitaristas" (Singer, 2009, p. 26).

La prueba moral exigida por el utilitarismo, por lo tanto, al contrario de las teorías morales sistémicas o discursivas, no parte de aspiraciones universales. Tampoco se preocupa por conceder a la autonomía del individuo - aun cuando parta de una concepción fundada en la intersubjetividad - un papel central en el examen del dilema filosófico. Lo que importa es centrarse en la idea de una igualdad amplia y en la resolución de los problemas concretos presentados, a partir de las condiciones empíricas ofrecidas para la resolución'. En las palabras de Singer, el centro de la propuesta utilitarista está justamente en la idea de la consideración acerca de intereses iguales: "la esencia del

Sobre el tema, Sandel, 2013b. 
principio de igual consideración de intereses es que en nuestras deliberaciones morales damos la misma importancia a los intereses parecidos de todos aquellos a quienes afectan nuestras acciones" (Singer, 2009, p. 32).

En el dilema del tren brasileño, la perplejidad extraída de una decisión como la adoptada por la concesionaria del servicio ferroviario es proporcional al asombro provocado por el enfoque del abordaje utilitarista, fundado en la exigencia de un raciocinio estratégico que, apenas por excepción, alcanza una universalización con relación a la solución de la colisión de las libertades en sociedad ${ }^{2}$. Al contrario de lo sostenido por las concepciones iluministas, en el utilitarismo clásico la autonomía parte de premisas de relevancia distintas para el intérprete, principalmente cuando envuelve intereses de alcance no solo individuales sino intersubjetivos. Es lo que permite a Peter Singer, aunque de forma lógica y coherente con los ideales regulatorios utilitaristas, comprender que "poseer una 'personalidad moral' no constituye una base satisfactoria para el principio de que todos los seres humanos son iguales". De acuerdo con Singer, si para los modernos la autonomía representa "la capacidad de elegir, de hacer y actuar según las propias decisiones" (Singer, 2009, p. 106), desde una concepción utilitarista, no necesariamente la autonomía sería considerada un principio moral básico, "ni tan siquiera un principio moral válido" (Singer, 2009, p. 106).

Sobre libertad y esfera pública, Taylor, 2014.
La cuestión propuesta para la discusión en el presente trabajo se refiere, precisamente, a la confrontación de los posicionamientos morales discursivos del derecho con la ética utilitarista y sus consecuencias jurídicas en el enfrentamiento de casos difíciles en el derecho3. $\mathrm{Y}$, especialmente, cuando se constatan situaciones en las que existe un aparente conflicto entre derechos de libertad y de igualdad. El foco del estudio está igualmente destinado al análisis del texto del Estatuto de la persona con deficiencia en el ordenamiento jurídico brasileño, en el que se propone una derogación significativa de un artículo del Código Civil brasileño por medio de una ley especial, al dejar de prever como incapaz a quien se presente como portador de deficiencia mental. La discusión académica aquí propuesta se preocupa por el hecho de que, en la derogación de un artículo normativo - fundada en un presupuesto de derecho a igualdad - , queda igualmente apartado el criterio del discernimiento como variable suficiente para la identificación de una situación de incapacidad civil ${ }^{4}$.

3 En el tema, Fried, 2007. Con misma preocupación, Rouanet, 2003.

4 Artículo original: "Art. $3^{\circ}$ Son absolutamente incapaces de ejercer personalmente los actos de la vida civil:

I - los menores de dieciséis años;

II - los que, por enfermedad o deficiencia mental, no tengan el necesario discernimiento para la práctica de tales actos;

III - los que, aun por causa transitoria, no puedan exprimir su voluntad."

Alteración normativa desde la vigencia de la Ley N. ${ }^{\circ}$ 13.146/15: "Art. $3^{\circ}$ Son absolutamente incapaces de ejercer personalmente los actos de la vida civil los menores de 16 (dieciséis) años. (Redacción dada por la Ley N. ${ }^{\circ}$ 13.146, de 2015) 
Por lo tanto, en una confrontación de la doctrina nacional con la perspectiva comparada, se pretende aquí hacer una reflexión dogmática sobre las consecuencias de la opción del legislador brasileño adoptada en el Estatuto de la persona con deficiencia. En una primera parte, se tratará de enfrentar el tema de la tensión existente entre la promoción de una autonomía de la persona y las cuestiones relacionadas al problema de la igualdad. En un segundo punto, se pretende enfrentar los temas del discernimiento, de la capacidad y de la opción por el enfoque del discurso jurídico, como medio de visualización del fenómeno jurídico.

\section{AUTONOMÍA E IGUALDAD}

Para alcanzar discusión semejante en cuanto a la extensión del concepto de autonomía y su concreción en las relaciones entre privados - que tangencia, de forma directa, el tema de la capacidad civil_- Habermas (2004b) parte del análisis de la condición científica más reciente que permite, en una combinación entre medicina reproductiva y técnica genética, arribar a un método de diagnóstico genético de preimplantación de embriones. El asombro de Habermas se relaciona con la constatación de que un progreso de las ciencias biológicas, asociado al desarrollo de la biotecnología, permite (i) ampliar las posibilidades de acciones humanas conocidas y (ii) posibilitar un nuevo tipo de intervención sobre la propia generación de la vida del

\footnotetext{
I - (Derogado);

II - (Derogado);

III - (Derogado)."
}

otro. O sea, se permite hoy someter un embrión que se encuentra en una etapa de ocho células a un examen genético de precaución, antes de la implantación, para, entre otras cosas, evitar el riesgo de transmisión de enfermedades hereditarias al momento de un procedimiento de fertilización in vitro. En este ambiente de interferencia sobre la generación de la vida del otro se sitúa, para Habermas, la frontera confusa "entre la naturaleza de lo que somos y la disposición orgánica que damos a nosotros mismos" (Habermas, 2004b, p. 17).

La filosofía práctica contemporánea, por lo tanto, parte de la preocupación por dilucidar, desde el punto de vista moral, qué criterios pasan a ser adoptados para analizar situaciones que puedan enfrentar los temas del igual interés de cada uno y de lo igualmente bueno para todos en la sociedad. Esto se vuelve un problema contemporáneo permanente por el hecho de que, por más que exista la convicción de que las teorías deontológicas contemporáneas expliquen de qué modo las normas morales deben ser fundamentadas y aplicadas -y en cuanto a eso quizá no haya dudas en relación a la construcción de la razón práctica-, aún no se observa una convicción del porqué existe el deber ser moral. Y, en cuanto a ello, como resalta Habermas, "seguramente la teoría moral paga un precio muy alto por dividir su trabajo con una ética especializada en las normas de la autocomprensión existencial" (Habermas, 2004b, p. 7).

Para quien no parta, por definición, de un modelo de moral perfeccionista, una 
respuesta estratégica a tal tipo de indagación — saber por qué debemos observar conductas morales a pesar de todo-. quizás esté fundada en una situación de riesgo. En la medida en la que, siguiendo a Habermas, reconocemos que los avances tecnológicos pasan a exigir un nuevo "margen de decisión" (Habermas, 2004b, p. 18) incluso en cuanto a los límites a la generación de vida humana, corremos un riesgo serio de tener que establecer un nuevo parámetro para la autocomprensión. O decidimos de forma autónoma, "según consideraciones normativas que se encuentran en la formación democrática de la voluntad" (Habermas, 2004b, p. 18), o podemos resultar sujetos a la arbitrariedad por soluciones utilitaristas "en función de preferencias subjetivas, que serán satisfechas por el mercado" (Habermas, 2004b, p. 18).

La doble dinámica de enfoque con relación a la dimensión de la autonomía del individuo, como individualidad y como intersubjetividad, aproxima la discusión filosófica del campo de análisis de la libertad en términos jurídicos. Cuando se habla de autonomía se está, en verdad, discutiendo una cuestión más amplia que la presupuesta en un derecho general de libertad por el individuo. Habermas es quien establece una distinción bastante clara: los conceptos se diferencian por el ámbito de su amplitud. Mientras la libertad es siempre subjetiva, porque se funda en las peculiaridades del individuo — sus "máximas de prudencia, por las preferencias o motivos racionales" (Habermas, 2004b) —, la autonomía es un concepto que presupone una estruc- tura de intersubjetividad determinada por máximas avaladas por la prueba de la universalización 5 .

Eso significa comprender que, para efectos de análisis del problema puesto dentro de las bases de un discurso jurídico, que esencialmente trabaja con categorías morales-pragmáticas, aunque se pueda reconocer la libertad del individuo en abstracto, es necesario que le sea posible visualizar también una autonomía en potencia, porque está autorizada la percepción como participante de una comunidad moral o "como una comunidad formada de individuos libres e iguales que se sienten obligados a tratar los unos a los otros como fines en sí mismos" (Habermas, 2004b, p. 13). Participar del discurso jurídico no importa, por lo tanto, en una simple verificación de presupuestos de libertad en sociedad por las elecciones realizadas de forma amplia. Es preciso que se reconozca autonomía al individuo, porque, al menos en potencia, existe el reconocimiento intersubjetivo de que tratamos, los unos a los otros, como fines en sí mismos.

\footnotetext{
Siguiendo a Habermas, "en cuanto a la libertad subjetiva, no es difícil imaginar que algunas personas puedan gozar de la libertad y otras no, o que algunas personas puedan ser más libres que otras. La autonomía, por el contrario, no es un concepto distributivo y no puede ser alcanzada individualmente. En este sentido enfático, una persona solo puede ser libre si todas las demás lo son igualmente. La idea que quiero subrayar es la siguiente: con su noción de autonomía Kant ya introduce un concepto que solo puede explicarse plenamente dentro de una estructura intersubjetivista" (Habermas, 2004a, p. 13).
} 
Así, toda y cualquier decisión acerca del dilema del tren, para quien parta de una concepción moderna de libertad fundada en un enfoque filosófico humanista, es antes la construcción de un juicio que no dispensa, para la situación concreta, el ejercicio de la prueba trascendental de Kant por una ética universal. Por eso se pregunta: ¿Es posible generalizar la conducta de mover el tren por encima del cuerpo extendido en las vías, aunque no se lo toque, sin ofrecer una razón suficiente para apartarse de un respeto al principio de dignidad a la persona humana más allá de su existencia con vida? ¿Debemos considerar, más allá de las condiciones estratégicas (fácticas y jurídicas) de los intereses de los directamente afectados por el dilema - la cuestión pre-ética de los utilitaristas - una interpretación moral previa que considere igualmente relevante los derechos de personalidad del cuerpo extendido en el suelo? ¿Y en qué medida tal discusión interfiere igualmente en el campo de la definición de capacidades civiles, cuando se aparta el criterio de la racionalidad para la universalización de conductas morales?

Lo que torna más complicado enfrentar en la contemporaneidad el tema de la autonomía es, justamente, que no siempre partimos de la misma definición acerca de las condiciones de interacción en sociedad. Y aquí ni siquiera se habla de una hipótesis de ausencia de espacio para la construcción del juicio, como en Arendt (1999), por el reconocimiento de la falta del espacio para el acto del pensar ${ }^{6}$. Tal

6 La referencia a Hannah Arendt se origina en los cuestionamientos de la autora con relación a realidad, para el debate propuesto, se encuentra presupuesta. La cuestión discutida es en cuanto a la propia extensión acerca de una definición del concepto de autonomía para la construcción de juicios morales o, inclusive, juicios eminentemente jurídicos, capaces de interferir de forma significativa en conflictos complejos, como por ejemplo en el campo de la bioética, en la definición de capacidades o en el reciente debate sobre el derecho de los animales no humanos, incluso para el reconocimiento de capacidad propia.

Hay quien comprenda, como Nussbaum, que la autonomía pueda ser una condi-

la actividad del pensar: "el impulso inmediato vino de haber asistido al juicio de Eichmann en Jerusalén. En mi informe hablé de la "banalidad del mal". Por detrás de esa frase, yo no sostenía ninguna tesis o doctrina, a pesar de estar vagamente consciente del hecho de que era contraria a nuestra tradición de pensamiento - literaria, teológica o filosófica - acerca del fenómeno del mal. (...) Estaba espantada con una manifiesta superficialidad del agente que tornaba imposible seguir el mal incontestable de sus actos hasta cualquier nivel más profundo de raíces y motivos. Los actos eran monstruosos, pero el agente, por lo menos el que ahora iba a ser juzgado, era absolutamente vulgar, ni demoníaco ni monstruoso. (...) Fue esta ausencia de pensamiento - que es una experiencia tan vulgar en nuestra vida cotidiana, donde difícilmente tenemos tiempo, para no hablar de la inclinación para parar y pensar- lo que despertó mi interés. ¿Es posible el obrar mal (tanto los pecados de comisión como los de omisión) ante la falta de no apenas 'bajos motivos' (como la ley los llama) sino de cualquier especie de motivos, de algún impulso particular del interés o de la voluntad? (...) ¿Puede el problema del bien y del mal, nuestra facultad de distinguir lo cierto de lo errado, estar en conexión con nuestra facultad de pensar?" (Arendt, 1978, p. 13). 
ción precaria de "existencia finita" (2013, p. 192) y que por eso apenas se vea fortalecida cuando exista una conciencia, e inclusive una condición de reconocimiento a priori, de una vulnerabilidad en el cuerpo social. Lo que representa, de cierta forma, un retorno al pensamiento antiguo basado en virtudes y restricciones, enseguida justificadas y fundadas en una justicia distributiva reformulada por la idea de "cooperación social" (2013). O incluso comprender, en la línea de Dworkin (2014), que es posible distinguir fronteras entre la buena vida y el bien vivir, dimensionando ideales éticos distintos para la vida con dignidad y para el alcance de condiciones fácticas suficientes (en la salud, en las relaciones, en las circunstancias económicas) para el desarrollo de una vida digna.

Más recientemente, Michael Sandel (2013a), igualmente, propuso la discusión del tema desde situaciones de ética aplicada, en las que plantea de forma crítica hipótesis adoptadas en la experiencia norteamericana de "mejoramiento genético" (2013a, p. 13) — desde la dualidad observada en los descubrimientos genéticos, sea como promesa de mejora a la salud, sea como dilema de manipulación de la naturaleza humana (2013a, p. 19) y de una nueva propuesta de eugenesia en el mundo contemporáneo por una ética sujeta a relativizaciones. La opción de Sandel, ante las situaciones extremas de análisis, es por una ética que implique ponderación frente a los casos presentados, aunque parta de una concepción de autonomía casi sacra: "ganaríamos más cultivando una valorización más amplia de la vida como dádiva que pide nuestra reverencia y restringe nuestro uso" (Sandel, 2013a, p. 133).

No es por acaso que se constata una cierta preocupación por las virtudes y un retorno a ideales antiguos sobre lo que debe ser contenido, aunque sea mínimamente, en la idea del "bien". La preocupación es justamente con la fuerza del argumento presentado por autores como Peter Singer a la base de una filosofía utilitarista que gana cuerpo en una visión más amplia de interés. Cuando se trata, de forma seria, de temas como la cuestión de la capacidad, del aborto y de la eutanasia, de la igualdad entre las especies - o sea, no apenas entre humanos - por el enfoque utilitarista, es seductora la construcción filosófica ofrecida que permite superar, por la idea de interés, cualquier frontera de cuestiones de justicia, principalmente en términos de igualdad, envolviendo animales o personas con determinadas incapacidades. Por otro lado, es extremadamente preocupante, como apunta Nussbaum, partir de una visión que "aliente a producir las mejores consecuencias generales como punto de partida correcto para la justicia política" (Nussbaum, 2013, p. 417)?

\footnotetext{
Tal presupuesto, inclusive, sería el elemento que permitiría explicar, para Nussbaum, cierta retracción a priori en la construcción de una concepción de autonomía: "realizar una pequeña lista de las capacidades centrales, como derechos fundamentales basados en la justicia, es un modo de posicionarse acerca del contenido. Pero es también, principalmente, un modo de anunciar nuestra contención delante de personas con concepciones diferentes" (Nussbaum, 2013, p. 419). En el tema, sobre el desarrollo de la dogmática civil, González, 1995.
} 
La cuestión, consecuentemente, es la de comprender en qué medida se deben establecer límites a priori a un ejercicio de libertad intersubjetiva y de qué forma deben estar justificadas razones serias a la restricción de toda y cualquier libertad, al mismo tiempo que se pueda potenciar la autonomía como un principio aún relevante para la moral en la sociedad contemporánea. Algo que escapa al enfoque utilitarista, incluso en la concepción más liberal de Peter Singer, en la medida en la que el problema de la justicia parte no de un foco central en el análisis de libertades $-\mathrm{y}$, por tanto, con ausencia de preocupación centrada en el valor de la autonomía- y sí en el análisis privilegiado de presupuestos de igualdad.

Y esta, tal vez, sea la cuestión perversa con relación a la construcción del argumento moral de fondo en el utilitarismo. Para alcanzarse una pretensión estratégica de cuño liberal —y así potenciar el mejor de los intereses para quien esté directamente relacionado con un conflicto, independientemente de juicios hipotéticos a priori-, la justificativa filosófica comprende una premisa valorativa de cuño igualitario amplio, capaz de crear niveles abstractos y meramente formales de igualdad en la misma proporción en la que genera un riesgo de destrucción significativa a la tradición humanista de construcción de valores a la existencia humana.

Cuando aquí se busca trabajar institutos y conceptos jurídicos caros a la modernidad, como el de la capacidad jurídica, por medio de una discusión nueva - el alcance de esta capacidad desde presupuestos de igualdad jurídica, como en la hipótesis de la reciente vigencia del Estatuto de las personas con deficiencia- es imprescindible que se comience el análisis por un debate sobre la propia posibilidad de este alcance, a partir de las categorías actuales disponibles para el estudio de una alteración de paradigma. Porque aquí, al final, lo que se está discutiendo es la efectiva posibilidad, en el mundo contemporáneo, de reconocer capacidad amplia al individuo desde estructuras fundadas en el reconocimiento de una igualdad formal y material a priori, por tanto, presupuesta abstractamente ${ }^{8}$.

8 De cierta forma, partiendo desde donde Sérgio Paulo Rouanet, en su Mal-Estar da Modernidade (1993) lanzó el debate - - (...) salvo mutaciones genéticas inesperadas, hombres y mujeres continuarán teniendo una anatomía propia. Las epidermis continuarán siendo blancas y negras y las tradiciones culturales serán mantenidas en su variedad. El Iluminismo no excluye la diferencia, pero excluye la diferencia como ideología" (Rouanet, 1993, p. 69)-, se busca identificar cuál posibilidad existe, fundada en una ética universal - cara a la modernidad-, de discutirse la posibilidad de una relativización del propio concepto de sujeto de derecho como centro de la evaluación del ordenamiento jurídico desde un concepto de racionalidad presupuesto, de forma que el estatuto de la capacidad sea abierto a una diversidad no apenas cultural —en el ámbito antropológico de la discusión propuesta y ni siquiera todavía resuelta filosóficamente por una ética aplicada-, sino también biológica y genérica de la propia especie. Por eso el tema no escapó a Luc Ferry cuando trató del problema del ecofeminismo o de la alabanza a la diferencia (Ferry, 2009), justamente como forma de abordar las dificultades de tratamiento de la materia sobre la diversidad entre humanos: "Él" (el tema) "es omnipresente en las universidades, donde contribuye poderosamente para hacer reinar el terror intelectual ejercido en nombre 
Esa es la dificultad: no resolvemos de forma adecuada, en el ámbito social de la modernidad, el problema de las diferencias entre seres humanos y queremos resolver hasta el problema de la diversidad entre las especies, lo que permite un debate propio, aunque afín, sobre la capacidad de animales no humanos, justamente, para universalizar conceptos diversos a los creados en torno de la capacidad del individuo y, hasta entonces, desde una característica considerada primordial a los modernos en la distinción de la especie: la razón. La discusión más reciente, por tanto, no se basa en la creación de una protección jurídica a los considerados incapaces - que, al menos del punto de vista formal, existe-, sino en discutir el mismo presupuesto de la situación de capacidad abstracta considerada, fundada en posiciones jurídicas predeterminadas y ahora desafiadas frente a la aprobación del Estatuto de la persona con deficiencia en el ordenamiento jurídico brasileño. Situación que, desde una igualdad legislativa presupuesta, termina por alejar cualquier diferencia de constitución de características físicas e intelectuales de los individuos con base en el discernimiento para la manifestación libre de la voluntad, dejando de reconocer, abstractamente, la "diferencia de derechos", acuñada por Ferry (2009, p. 205), que sería capaz de universalizar la búsqueda por una igualdad material por medio de estatutos jurídicos especiales.

de lo 'políticamente correcto' y del derecho a la diferencia que se extiende fácilmente por la reivindicación de una diferencia de derechos" (Ferry, 2009, p. 205).
Así, la complejidad de abordaje de la materia no puede estar fundada en la simple simpatía que se pueda desarrollar por el tema de la igualdad jurídica9. Es preciso un esfuerzo superior del intérprete jurídico para vencer el problema de la diferencia entre los individuos, ya que no se trata apenas de un problema de identificación del trazo distintivo de la razón entre las personas, sino de la medida de real protección pretendida en abstracto para que se permita, efectivamente, ver identificada una situación de distinción jurídica, para fines de tutela, ante la diferencia. Esta circunstancia jurídica permite, por la extensión y estabilización del argumento, que se avance en el examen del tema de la distinción entre los seres en razón de la racionalidad, incluso para el debate sobre la capacidad de los animales no humanos —ámbito de discusión, sin embargo, que demandaría trabajo propio de análisis jurídico-.

Para enfrentar el debate sobre el tema de la capacidad, es fundamental que se examine el problema de la racionalidad para los modernos, en la medida en la que se trata de una circunstancia cara a la distinción entre los seres. Aunque se pueda identificar, biológicamente, por el ejercicio de la experimentación empírica, trazos racionales, o hasta de elección libre, incluso al animal no humano, la di-

9 Como bien aclara Ferry, "la simpatía no es sino un hecho que choca contra otros hechos y, como tal, nada justifica: están los que aman la corrida de toros de facto, los que la reprueban de facto y, en caso que se quiera decidir de jure, será preciso elevarse apenas por arriba de la esfera de lo fáctico para buscar argumentos (Ferry, 2009, p. 236). 
ficultad de extender estatutos jurídicos propios de la humanidad - por tanto, que estén vinculados al concepto de persona - al animal no humano, se traduce en una barrera hasta el momento insuperable desde la óptica de la modernidad. Se explica. Es que todavía no se consigue vencer, con relación a otras especies de animales, el problema intrínseco de la naturaleza con relación a su determinación sobre la condición instintiva. O sea, la posibilidad de que, principalmente en situaciones extremas o de efectiva elección entre especies, haya alteridad para una elección o hasta un juicio justo, que pueda incluir, inclusive, restricciones efectivas a la propia especie en beneficio de otra, justamente porque es posible la comprensión de que una supervivencia universal se presente como necesaria. Este carácter de universalidad, más allá de la propia especie, es lo que permanece como un trazo distintivo de la capacidad humana de determinación con relación a los demás animales.

Sin embargo, hay que hacer alguna ponderación en cuanto a esta intervención calificada del ser humano sobre la naturaleza. Aquí no se está defendiendo el hecho de que el ser humano efectúe este control sobre la naturaleza de las especies con maestría — por el contrario, existen ejemplos suficientemente caracterizadores de su capacidad destructiva- - Lo que se pondera, desde categorías universales, es el argumento pertinente a la distinción del trazo de humanidad en la sociedad moderna. Por lo menos para alejar, hasta la generación de nuevos paradigmas, la alteración de estatutos jurídicos tan caros como el de la capacidad civil. Y en ello algunos conceptos modernos de libertad se configuran como necesarios para mejor explicar la defensa de tal punto de vista, con repercusiones a ser consideradas en la segunda parte de este ensayo con relación a la cuestión del "discernimiento".

En el centro de la discusión propuesta está predispuesto el debate de cuánto es posible reconocer una efectiva autonomía a los seres, para que puedan alcanzar y desarrollar una capacidad como sujetos de derechos. Un reconocimiento que no se agota en la protección al medio ambiente y a los animales de una forma más específica, sino que busca identificar si es posible hablar de respeto a una libertad subjetiva propia, pues se identifica una autonomía como ente propio. Y, por tanto, como alguien capaz de participar de un diálogo "amplio y apuntado hacia el acuerdo", como destaca Habermas, en el que se exigía una "virtud cognoscitiva de la empatía con relación a nuestras diferencias recíprocas en la percepción de una misma situación" (Habermas, 2004a, p. 10). Esta parece ser la clave de la discusión del problema. O sea, saber si es posible, por la experiencia científica contemporánea, reconocer a los seres de una forma amplia, en virtud de la identificación de aspectos cognoscitivos, sensitivos y culturales complejos — que puedan, incluso, trascender a la simple condición extintiva de la supervivencia humana-, la calidad de participantes de un discurso jurídico con la autonomía necesaria para el reconocimiento de una capacidad jurídica propia, independientemente de la 
representación por terceros. Un debate que surge en la experiencia dogmática y jurídica brasileña reciente con la sanción del Estatuto de la persona con deficiencia (Ley N. $\left.{ }^{\circ} 13.146 / 15\right)$.

\section{DISCERNIMIENTO, CAPACIDAD Y EL ESTATUTO DE LA PERSONA CON DEFICIENCIA}

Habermas reconoce la dificultad para enfrentar el problema de las restricciones de conducta cuando analiza, de acuerdo con los ejemplos antes dados, la posibilidad de una autolimitación normativa en las cuestiones referentes a la vida embrionaria. Aclara que esta interferencia, de hecho, "no puede volverse contra las intervenciones de la técnica genética en sí" (Habermas, 2004b, p. 61), incluso por no tratarse de un problema de la técnica, sino del alcance y del modo de intervención que serán efectuados en concreto. Pero no por ello adopta el autor una postura favorable a la eugenesia liberal sin ponderación previa. Al contrario, propone para casos de interferencia máxima e irreversible sobre la generación del otro - como en el caso mencionado de investigación clínica con embriones desde la posibilidad de un diagnóstico genético de preimplantación-, cuando todavía existan fronteras amplias entre la investigación científica y las motivaciones para tanto, que sean establecidos parámetros a priori más rígidos para el caso de una eugenesia negativa (Habermas, 2004b, p. 96), desde luego, permitiendo la verificación de límites a la propia investigación, en caso de que no se presenten objetivos claramente terapéuticos en la intervención sobre la generación de la vida del otro.
Es lo que garantiza, según Habermas, en las condiciones fácticas actuales, que se evite una instrumentalización sobre la vida del otro cuando aún no exista certeza acerca de un pronóstico de intenciones y resultados científicos. El ejercicio está justificado por la filosofía de bases discursivas. Si hay interés en la continuidad de una comunidad moral, puesto que, comprendida la necesidad de mantenimiento de pretensiones de corrección a las conductas individuales para compatibilizarlas a la vida en sociedad, permanece siendo relevante alcanzar cierto acuerdo en términos deontológicos, justamente porque se torna necesario tolerar la convivencia social. Buscar describir el fenómeno jurídico desde el discurso práctico —y su versión especial, del discurso jurídico (Alexy, 2012) —, impone el compromiso al intérprete de privilegiar el binomio de la universalidad-particularidad, cuyo centro de la discusión se encuentra en la promoción de un derecho general de libertad y en la posibilidad amplia y abierta de problematizar sobre deseos, opiniones e intereses. El ambiente de esta discusión, aunque pueda ser limitado a determinadas condiciones, no es, con todo, un universo reducido a los intereses en juego.

No se puede partir, como consecuencia, de una limitación estratégica que tenga contornos establecidos desde un proyecto determinado - lo que podría conducir necesariamente a la comprensión de que lo que importa apenas son los intereses particulares de los afectados por el dilema (Singer, 2009, p. 32) — . Hay un compromiso más amplio relacionado con la prueba de la racionalidad en términos universa- 
les, aun cuando la discusión propuesta sea aparentemente de menor relevancia. Por cierto, la gran mayoría de las veces, el mismo sistema ofrecerá respuestas potentes para la solución de los conflictos, pero para la porción específica de casos que demandan una respuesta distinta, sea porque aún no fueron probados, sea porque ofrecen peculiaridades propias, es fundamental que no se pierda la dimensión de la racionalidad en la construcción de una respuesta posible. Y una respuesta que no tenga pretensiones individuales en su amplitud — aunque que pueda ser "individualizadora en su objetivo" (Rouanet, 1993, p. 33) - , sino que potencialmente reconozca un alcance igualmente institucional a la solución que venga a ser adoptada en concreto $^{10}$.

10 Rouanet, identificando el malestar del mundo contemporáneo, justamente frente a la construcción de una filosofía antisubjetivista que es, en su esencia, antihumanista (Rouanet, 1993, p. 64) —, apunta de forma clara ser lo particular, y no lo universal, el gran adversario de una ética universalista. Y eso ocurre no por la destrucción de la particularidad, lo que sería típico de regímenes totalitarios, sino por la creación incesante de la particularidad (Rouanet, 1993, p. 65). Es lo particular que "transfigura ideológicamente particularidades empíricas existentes, o crea esas particularidades (...), balcanizando el mundo para mejor controlarlo" (Rouanet, 1993, p. 65). Lo que permitiría, incluso, una justificación de la particularidad por la banalización que lo universal podría, teóricamente producir. Circunstancia, sin embargo, que no coincide, por excelencia, con la filosofía discursiva, como bien resalta Rouanet: el universalismo iluminista "no preconiza el genocidio de las particularidades existentes. Lo que rechaza es la creación ideológica de particularidades fraudulentas, o el uso ideológico de particularidades reales, como pretexto para la dominación o para acallar la crítica" (Rouanet, 1993, p. 69).
Se parte de la comprensión de que, prima facie, se impone el cumplimiento de un principio que exige la mayor medida posible de libertad general de acción. Pero tal amplitud de libertad corresponde, proporcionalmente, a una misma extensión de libertad negativa. Un concepto jurídico que se establece desde la posibilidad de siempre sufrir restricciones y que permite una preocupación permanente por la composición de libertades confrontadas en el espacio público. No se puede pretender que entre lo que es común a todos haya espacio para, arbitrariamente, construir soluciones jurídicas con base en valoraciones entre lo mejor y lo peor, desde la perspectiva exclusiva de los involucrados. Es imprescindible volver al examen de la razón práctica demostrada por el problema concreto que incluye los derechos fundamentales. Y, en tal caso, no por medio del criterio de lo que es bueno, sino del criterio de lo que es correcto. La corrección defendida no es la que corresponda a un ideal de validez incondicional o absoluta. Se trata, frente a la perspectiva del discurso, de una pretensión de corrección dispuesta de forma ideal, pero también condicionada y abierta a las circunstancias propias del discurso particular ${ }^{11}$.

\footnotetext{
11 O como aclara Habermas en sus Comentários à ética do discurso, "en el caso de la razón práctica, poder dilucidar los elementos de un universo social sobre lo que es mejor para los mismos y sobre la forma como deben reglamentar su vida en conjunto, abrirá, entonces, la posibilidad a un conocimiento práctico que es ciertamente construido desde la perspectiva intrínseca a nuestro universo, pero que simultáneamente trasciende ese horizonte" (Habermas, 1991, p. 89).
} 
Esta es la flexibilidad esperada, desde una fundamentación racional, por el discurso en la perspectiva de análisis pragmático de un caso concreto. Es por ello que no hay que hablar de un efectivo ejercicio de racionalidad cuando se observan decisiones fundadas en concepciones estrictamente utilitaristas en el Derecho. Lo que sostiene la pretensión de corrección por el discurso - y, por tanto, asegura unidad y autonomía al sistema jurídico—es, justamente, la posibilidad de una aproximación entre la simultánea protección de libertades y la garantía de seguridad jurídica, por la elección racional de una solución correcta a todo el caso empírico propuesto para un análisis jurídico. Algo que de ningún modo combina con el atropello del concepto de capacidad a plena luz del día.

No por otro motivo se cuestiona la reciente edición del Estatuto de la persona con deficiencia (Ley N. ${ }^{\circ}$ 13.146/15) en Brasil, cuando suprime, bajo el presupuesto de la igualdad de tratamiento entre las personas, el texto de los incisos del enunciado normativo del artículo $3^{\circ}$ del Código Civil brasileño, extirpando del Código Civil el criterio del discernimiento - y, por lo tanto, de la idea de racionalidad - para la determinación de la capacidad civil. Por la alteración del texto, donde antes se reconocía incapacidad absoluta a los que, por enfermedad o deficiencia mental, no tuviesen el necesario discernimiento para la práctica de actos de la vida civil (inciso II del artículo $3^{\circ}$ ), hoy se comprende que no cabe cualquier discriminación normativa a priori en razón de las condiciones de intelección del individuo, dejando el texto legal de ofrecer criterios suficientes para la averiguación de la real capacidad del individuo a la manifestación libre y consciente de la voluntad. Donde antes había discernimiento, hoy hay igualdad material presupuesta sin cualquier condición previa de averiguación suficiente sobre la efectiva autonomía de la persona en el examen del caso concreto. No se puede reconocer para el caso que se haya presupuesto, filosóficamente, la adopción de un enfoque eminentemente funcionalista con relación a la concepción de autonomía para las cuestiones que envuelven la capacidad de la persona, en la medida en que se realza una idea amplia de igualdad formal y material entre los individuos, en detrimento de una ponderación necesaria acerca de criterios claros para el establecimiento de las condiciones en cuanto a la posibilidad de expresión de la voluntad propia.

Pero hay todavía un peligro más inmediato, con relación a la interpretación de la supresión de la expresión discernimiento de la definición de capacidad de los individuos: la posibilidad de que, en ausencia de un criterio antes orientador de la interpretación, esté abierta la oportunidad para la discrecionalidad irrestricta por parte del intérprete judicial. Tal deducción es posible por el hecho de que la Ley $N{ }^{\circ}{ }^{\circ} 13.146 / 15$, al prever la derogación expresa del reconocimiento de incapacidad a quien, por enfermedad o deficiencia mental, no tenga "el necesario discernimiento" para la práctica de actos civiles, deja de establecer cualquier criterio científico suficiente para la toma de decisión, cuando sea necesario, para la 
correcta aprehensión de la manifestación libre de voluntad. En lugar de ello, prevé un sistema de toma de "decisión apoyada", en la que se establece la posibilidad de expresión de la voluntad por medio de terceros a quienes sea confiada una especie de curatela mitigada bajo supervisión judicial. La cuestión es que no hay una determinación abstracta, al contrario de lo anteriormente previsto en el Código Civil, de cuándo tal circunstancia deba ser observada en concreto, justamente porque no hay ninguna línea divisoria de comprensión del efectivo comprometimiento de la voluntad, principalmente cuando existen intereses de terceros o situaciones de protección a la personalidad del sujeto con deficiencia.

Véase que la idea de discernimiento anteriormente consagrada en la dogmática a la luz del ordenamiento jurídico brasileño - aunque pasible de interpretaciones con cierta dificultad - había alcanzado un nivel de argumentación suficiente para la construcción del concepto de autonomía, permitiendo el equilibrio entre la efectiva posibilidad de expresión de la voluntad y la interna disposición en cuanto al interés efectivo a la manifestación de esta voluntad. Y aquí la idea de descarga que se reconoce es con relación al alcance argumentativo antes observado en la construcción del concepto de autonomía por medio de la idea de discernimiento. Esto quiere decir, como acentúa Alexy (2012, p. 257), que, no habiendo una razón especial, se torna innecesario para el intérprete comprobar lo que ya se tiene como acordado con relación a la justificación alcanzada por determinado enunciado dogmático. Al mismo tiempo en que tal función refuerza un sentido de universalidad pretendido al enunciado normativo, permite que se reconozca una relevancia esencial al acuerdo, alcanzado por la interpretación, acerca del enunciado dogmático en discusión.

La función de descarga al enunciado dogmático autoriza que se visualice una aparente rigidez con relación a una fundamentación jurídica, porque mantiene estable la fuerza semántica de un enunciado normativo con relación a una situación universal. Sin embargo, no impide que sea propuesto un nuevo acuerdo sobre el mismo enunciado en la medida en que son identificadas otras funciones específicas de los enunciados dogmáticos, como la función de progreso. Pero impone, en similar medida, la exigencia de una carga argumentativa de igual relevancia para el establecimiento del acuerdo, y esto es esencial. La ausencia de observancia a la función de descarga por la dogmática jurídica no justifica, pero puede facilitar, la inclinación a una discrecionalidad arbitraria por parte del intérprete, permitiendo la complementación de enunciados normativos exclusivamente por argumentos empíricos que, por sí solos, no se presentan suficientes para la construcción de una razón práctica.

Lo que se busca rescatar para la correcta interpretación normativa, con la aprobación del Estatuto de la persona con deficiencia, es el concepto de autonomía, observado como determinante para la interpretación de cualquier acto jurídico y que, por tanto, refleja la situación de 
la capacidad civil prevista para efectos de una interpretación jurídica, como por ejemplo, la orientada en el artículo 112 del Código Civil brasileño con relación a los actos de la vida civil. O sea, en el sentido de que "en las declaraciones de voluntad se atenderá más a la intención en ellas contenida que al sentido literal del lenguaje". Esto explica la dificultad de compatibilización de lo que hoy es previsto de forma general con relación a todos los individuos - y que refleja, inclusive, situaciones de protección a la vulnerabilidad, construidas históricamente- con la situación nueva prevista en el Estatuto de las personas con deficiencia, alejando justamente el criterio del discernimiento para fines de caracterización de una condición de vulnerabilidad extrema. Esta circunstancia ya no es más presupuesta a quien esté en situación reconocida de "impedimento de largo plazo de naturaleza física, mental, intelectual o sensorial, el cual, en interacción con una o más barreras, puede obstruir su participación plena y efectiva en la sociedad en igualdad de condiciones con las demás personas" (artículo $2^{\circ}$ de la Ley N. $\left.{ }^{\circ} 13.146 / 15\right)$.

El temor es que la orientación hoy promovida para la interpretación en términos de capacidad, cuando se trate de persona con deficiencia, quede condicionada a mitigar la protección jurídica prevista y reconocida por la idea de discernimiento. Y, además, que sea contraria de lo que se presenta como la efectiva finalidad de la aprobación de la ley especial. Tal preocupación se apoya, justamente, en la derogación expresa del inciso II del artículo $3^{\circ}$ del Código Civil brasileño, aliada a la ausencia de previsión específica de un criterio sustitutivo de interpretación, en la medida en que la Ley N. ${ }^{\circ} 13.146 / 15$ se limita a ofrecer, para la orientación de la discrecionalidad judicial, la adopción de un procedimiento de "decisión apoyada". Por esta es considerada, para el reconocimiento de una manifestación libre de la voluntad, la opinión de terceros que sean de confianza de la persona con deficiencia, nombrados específicamente para tal finalidad. En la hipótesis de ocurrencia de conflicto de intereses entre los terceros a quien fue confiada la adopción de la decisión, es necesario, substitutivamente, establecer un proceso específico de evaluación de la decisión tomada en concreto por medio de un equipo de técnicos. Del mismo modo, en tal hipótesis no existe en la Ley el ofrecimiento de cualquier criterio a priori para la distinción de la situación de dificultad del individuo en la identificación de una manifestación libre de la voluntad, en el examen de la situación concreta de análisis. Es más grave: no prevé el Estatuto de la persona con deficiencia ninguna forma de responsabilizar a los terceros que acaben, efectivamente, tomando decisiones arbitrarias o interesadas en nombre de la persona con deficiencia.

Lo que se acentúa, por consecuencia, es que aunque el Estatuto de la persona con deficiencia haya permitido colocar, en lugar destacado, la situación de promoción de igualdad formal a personas con deficiencia, dejó de considerar, especialmente, a aquellos que presentan déficit cognoscitivo relevante para la toma de decisiones con relación a actos de la vida 
civil, un criterio consagrado en la dogmática para fines de protección al libre desarrollo de la personalidad — como en la hipótesis del concepto de discernimiento- - Esto generó, al contrario de lo que se pretendía, inseguridad jurídica. Una situación de laguna normativa que, en caso de que no se corrija por la interpretación posible de las cortes judiciales, por el mantenimiento, en concreto, del criterio del discernimiento como distintivo a las situaciones de capacidad civil, permitirá, inclusive, la desproporción de interpretación con relación a otras situaciones de vulnerabilidad, que reciben protección específica por medio de estatutos jurídicos propios conforme la posición jurídica considerada, como en la hipótesis de personas de edad avanzada, consumidores, niños y adolescentes. De cierta forma, una opción legislativa que, no siendo muy diferente a la decisión adoptada en el dilema del tren brasileño, tiende, por la interpretación, a evidenciar un cariz utilitarista peligroso en el enfrentamiento del tema de la autonomía con relación a los derechos de personalidad, poniendo en riesgo, bajo aparente privilegio de una igualdad, la seguridad jurídica de derechos civiles individuales.

\section{CONCLUSIONES}

Debe comprenderse, efectivamente, que se torna cada vez más difícil sostener pretensiones de corrección moral en una vida de relación marcada por la virtualidad y por avances tecnológicos fantásticos que, inclusive, aumentan considerablemente las posibilidades de permanencia de la vida sobre el planeta. La experiencia humana, sin embargo, presenta una tradición histórica que nos permite constantemente desconfiar del alcance dado a los intereses individuales cuando están ausentes compromisos morales a priori. Y, principalmente, cuando ignoramos aquello que adquirimos como herencia histórica en nombre de una corrección de rumbos, desde el establecimiento de premisas de comparación igualitaria fundada, a veces, en un total desconocimiento acerca de los "pares de comparación" electos.

Lo ideal es que se pueda, con la cautela suficiente, efectivamente dar crédito a las conquistas filosóficas de la humanidad en los últimos siglos, no desconociendo la posibilidad de una permanente alteración de paradigmas a que se someten las estructuras vinculadas a la moral. Pero mientras no se vea superado por alternativas distintas y suficientes en la construcción del pensar, se mantiene la creencia en el valor intrínseco reconocido a la concepción de autonomía para los modernos. Aunque sean necesarias adaptaciones constantes al concepto, principalmente cuando se necesita la ponderación en términos de definiciones de capacidad y de igualdad entre seres para situaciones puntuales de análisis.

Aunque es seductora, para la consideración acerca de pretensiones concretas en un universo restricto de partícipes, la solución utilitarista fundada en un raciocinio de construcción de soluciones "pre-éticas" y de ponderación acerca de los mejores intereses, no alcanza para las situaciones complejas un sentido de 
universalidad a priori que permita que se reconozcan riesgos significativos a la protección de derechos fundamentales. El discurso práctico —y su versión jurídica para fines de argumentación sobre casos concretos - , en el otro extremo, aunque imponga ajustes permanentes para intereses de igual tratamiento, no abandona la premisa de la universalidad y en ello potencializa lo que existe de autónomo en el individuo, permitiendo el desarrollo li bre de su personalidad. Una circunstancia que posiblemente justifique la explicación de por qué necesitamos continuar apostando en un acuerdo moral de conductas bajo bases universales.

Específicamente con relación a la alteración propuesta al instituto de la capacidad civil en el ordenamiento jurídico brasileño por la Ley $N^{\circ}{ }^{\circ} 13.146 / 15$, con la eliminación del criterio del discernimiento para la determinación de la capacidad civil, se observa que hubo una clara opción del legislador por un enfoque utilitarista del Derecho. Donde antes había discernimiento, hoy hay igualdad formal presupuesta sin cualquier condición previa de averiguación suficiente sobre la efectiva autonomía de la persona en el examen del caso concreto. Se prestigia una idea de igualdad formal genérica en detrimento de una ponderación necesaria acerca de criterios claros para el establecimiento de las condiciones de expresión de la voluntad propia.

Por la lectura filosófica del discurso jurídico, en que la racionalidad asume un papel relevante para la construcción de la argumentación en concreto, la autonomía debe corresponder siempre a una condición de intersubjetividad, que se determina por máximas avaladas por la prueba de la universalización del conocimiento. En esa perspectiva, es fundamental que se rescate, para la correcta interpretación jurídica, el concepto de discernimiento consagrado por la dogmática civil, siendo observada la función de descarga presupuesta en la argumentación pertinente al libre desarrollo de la personalidad humana. Una situación actual de laguna normativa que, en caso de que no se corrija por la interpretación posible al examen del caso, podrá generar, inclusive, una situación de desproporción de protección jurídica con relación a otras condiciones de vulnerabilidad tuteladas por el ordenamiento jurídico brasileño.

\section{REFERENCIAS}

Alexy, R. (2012). Teoría de la argumentación jurídica. Madrid: Centro de Estudios Políticos y Constitucionales.

Arendt, H. (1978). A vida do espírito. Pensar. Lisboa: Piaget.

Arendt, H. (1999). Eichmann em Jerusalém: um relato sobre a banalidade do mal, Sao Paulo: Companhia das Letras.

Duarte, L. (2015). Morreu na contramão atrapalhando o tráfego. Porto Alegre: Jornal Zero.

Dworkin, R. (2014). A raposa e o porco-espinho: justiça e valor. Sao Paulo: Martins Fontes.

Ferry, L. (2009). A nova ordem ecológica: a árvore, o animal e o homem. Río de Janeiro: Difel.

Foot, P. (2002). Moral dilemmas and other topics in moral philosophy. Oxford: Clarendon Press. 
Fried, B.H. (2007). What's morality go to do with it. Harvard Law Review, 120 (3) 53-61.

González, C. P. (1995). Los desafíos actuales del paradigma del derecho civil. Estudios Públicos, 60, 327-348.

Habermas, J. (2004). A ética da discussão e a questão da verdade. Sao Paulo: Martins Fontes.

Habermas, J. (1991). Comentários à ética do discurso. Lisboa: Piaget.

Habermas, J. (2004). O futuro da natureza humana. Sao Paulo: Martins Fontes.

Nussbaum, M. (2013). Fronteiras da justiça. Deficiência, nacionalidade, pertencimento à espécie. Sao Paulo: Martins Fontes.
Rouanet, S. P. (2003). Ideias -Da cultura global à universal. Sao Paulo: Unimarco.

Rouanet, S.P. (1993). Mal-estar na modernidade. Sao Paulo: Companhia das Letras.

Sandel, M. (2013a). Contra a perfeição. Ética na era da engenharia genética. Río de Janeiro: Civilização Brasileira.

Sandel, M. (2013b). Justiça. O que é fazer a coisa certa. Río de Janeiro: Civilização Brasileira.

Singer, P. (2003). Desacralizar la vida humana: ensayos sobre ética. Madrid: Cátedra.

Singer, P. (2009). Ética práctica. Madrid: Akal.

Taylor, C. (2014). Argumentos filosóficos. Sao Paulo: Ediciones Loyola. 